\title{
Mobile Money Use In Ghana: An Assessment Of Its Relevance In The Financial Inclusion of Rural Communities
}

\author{
Fiasorgbor A. Doris \\ Department of Rural and Community Development, Faculty of Development Studies, \\ Presbyterian University College, Ghana \\ Tettey Caroline \\ Department of Environment and Natural Resources Management \\ Faculty of Development Studies, Presbyterian University College, Ghana
}

\begin{abstract}
Mobile money offers new possibilities for making financial services more inclusive in Africa, especially in rural Africa. Unlike conventional banking and financial services, mobile network operators (MNOs) have made huge investments to create networks that reach further and deeper into rural areas historically marginalized in an effort to satisfy their demand to communicate. Infrastructure changes in rural areas are external factors that may force new models for the mobile services. Since 2005, a new technology-mobile money-has become available in over eighty (80) countries worldwide. Mobile money (m-money) is a product that allows clients to use text messages to store value in an account accessible by the handset, convert cash in and out of the stored value account, and transfer value between users. As compared with the traditional means of sending and receiving money within many developing countries, such as Western Union and MoneyGram, the postal service or delivery by friends or family, m-money substantially reduces the costs of transferring money. M-money offers a new potential mechanism for increasing the financial inclusion of the world's poor. The main objective of this investigation is to critically examine mobile money usage and its relevance in the financial inclusion of rural communities. The generally attained educational level by the participants is Junior high school/Middle school qualification. Deposits, withdrawals (cash-in and cash-out), fund transfers and airtime purchase were the most patronised services. Results from the focused group discussion (FGDs) also showed that participants had used the mobile money services and the most used services were the funds transfer (receiving remittances) and buying airtime. The study also found that most of the participant sent and received mobile money compared to those that had either only sent or only received. Mobile money service has improved the financial inclusion of rural folk as demonstrated by the access and use of mobile money by the rural people. The researchers recommend that mobile money service providers should educate rural people to save through mobile money service.
\end{abstract}

Keywords: Mobile money, financial services, mobile network operators, financial inclusion, rural Ghana, Aboabo

\section{INTRODUCTION}

As mobile phones proliferate around the developing world, new services are emerging as mobile network operators (MNOs) diversify services to compliment voice and SMS in a progressively competitive environment where the goal is improving customer retention and reducing toss (Mendes, Alampay et al. 2007). A prominent emerging service is mobile moneya term used to loosely refer to money stored using the SIM (subscriber identity module) as an identifier as opposed to an account number in the conventional banking sense. A notational equivalent in value is then kept on the SIM within the mobile phone, which is also used to 
transmit payment instructions. The corresponding cash value is physically held by the MNO, a bank or another third party depending on the business model (Donner and Tellez, 2008). MNOs and their agents provide an interface between the two sides through cash-out (issuing cash on demand) or cash-in functions providing exchangeability between mobile money and cash (Morawczynski, 2009).

Mobile money offers new possibilities for making financial services more inclusive in Africa, especially in rural Africa. Unlike conventional banking and financial services, mobile network operators (MNOs) have made huge investments to create networks that reach further and deeper into rural areas historically marginalized in an effort to satisfy their demand to communicate as noted by Mas and Kumar (2008). According to Leishman (2010) infrastructure changes in rural areas are external factors that may force new models for the mobile services.

Since 2005, a new technology-mobile money-has become available in over eighty (80) countries worldwide. Mobile money (m-money) is a product that allows clients to use text messages to store value in an account accessible by the handset, convert cash in and out of the stored value account, and transfer value between users (Aker and Mbiti, 2010). As compared with the traditional means of sending and receiving money within many developing countries, such as Western Union and MoneyGram, the postal service or delivery by friends or family, mmoney substantially reduces the costs of transferring money.

M-money offers a new potential mechanism for increasing the financial inclusion of the world's poor. First and foremost, since m-money can reduce the costs associated with money transfers, it can allow households to send or receive money when it is needed, thereby improving households' ability to share risk (Jack and Suri 2011; Mirzoyants (2012) Beyond money transfers, m-money could also be used to create a secure pseudo-savings account, where individuals can deposit smaller savings amounts for more immediate needs (Oluwataya, 2013). As the "account" is password-protected, the m-money savings channel could offer greater security (as compared with savings under the mattress) while having increased access (as compared to the annual "share out" of savings clubs). In addition, m-money could encourage individuals to save for particular objectives.

\section{Literature Review}

\section{STUDY OBJECTIVES}

Divergent from the great enthusiasm about the prospects for mobile money to address the financial needs of the poor, there is a shortage of studies that investigate actual financial needs of the poor (Donner and Tellez 2008; Duncombe and Boateng 2009). Even amongst the growing number of studies reporting on various mobile money implementations around the world (Wishart 2006 and Morawczynski, 2009), only a few tend to depend on data from actual adoption and usage of the various systems (Ivatury and Pickens 2006 and Morawczynski 2009). Donner \& Tellez decry the lack of scholarly research on adoption and impact of mobile payments in the developing world and highlight the need to consider the social, economic and cultural environments within which such systems operate (Donner and Tellez 2008). While the focus on policy and regulations that facilitate innovation is important (Ndiwalana and Popov, 2008), taking into account actual needs, usage and varying contexts can only help improve mobile money adoption. In addition, this can highlight new opportunities for MNOs and other innovators to help the poor by transforming mobile money beyond basic money transfers. It is towards this goal that this fact-finding study seeks to make an input. 


\section{Benefits derived from Mobile Money}

Since 2005, a new technology which has been mobile money has become available in over eighty countries worldwide. Mobile money (m-money) is a product that allows clients to use text messages to store value in an account accessible by the handset, convert cash in and out of the stored value account, and transfer value between users as compared with the traditional means of sending and receiving money within many developing countries, such as Western Union and Money Gram, the postal service or delivery by friends or family, m-money substantially reduces the costs of transferring money (Aker and Mbiti, 2010).

\section{Saving}

Mobile money serves as a phone-cum savings account, thus enabling people without a formal bank account to engage in a safer and more efficient savings mechanism. It actually improves efficiency and regularity of savings (Nandhi, 2012).

Yang (2008) revealed that incomes for rural mobile money users increased due to remittances which also led to higher savings. Demombynes and Thegeya (2012) demonstrated the possibility of mobile money increasing savings while Jack and Suri (2011) assert that mobile money users saved to store funds safe from dangers of theft and inaccessibility to other family members. They further postulate that savings have the potential of adding social value to those constrained by cost opening a bank account and large distance between their household and the closest formal savings establishment (Jack \& Suri, 2011).

Aryeetey (1994) observes that Susu collectors put the bulk of their daily receipts into commercial bank accounts, retaining some to return to clients who need funds before the end of the month and some for their own short-term business transactions. In one (bank) branch, such deposits reached $40 \%$ of total demand deposits. Nonetheless, bank managers, largely unaware of the collection activities of account holders, have done little to facilitate deposits by Susu collectors.

The low savings in Ghana can also be attributed to the existence of credit opportunities. Although there is not much opportunity to access credit in the formal financial sector, family ties nuclear and extended, relationships and the community-centeredness of the Ghanaian society eases the access to credit in the informal sector. Over half of household loans come from relatives, friends and neighbours.

Not only physical distance from banking institutions but also high minimum deposit and balance requirements have plagued the Ghanaian banking sector and thus accounting for the low savings rate over the years. It is sad to say that financial liberalization in Ghana did not focus on increasing domestic savings but rather reducing inflation among other things (Adams Jr. and Cuecuecha, 2013).

\section{Improved Remittance}

Mobile money service allows users to benefit from remittances from family members and friends living abroad. This alone, assuming all other factors remain constant, will results in improved economic well-being as the poor will get a source of income (Alleman and Rappoport, 2010). Demombynes and Thegeya (2012) noted that the use of mobile money increased money flow by enhancing local consumption for the rural folks rebuffing economic activity. It is further asserted that the flow of remittances to rural areas increase economic activity by empowering 'just-in-time' transfers that make money available when it is needed. 


\section{Reduced transaction costs}

Costs refers to the cost savings and operational efficiency which a customer or firm may accrue as a result of adoption of technology (Boardi, Boateng, Hinson and Epoku , 2007). Transaction costs are the costs related to using the system for example costs associated to sending and receiving money (Boateng, 2011). Mas and Radcliffe (2011) noted that mobile banking turns fixed costs into variable costs but enough to allow the agent to promote the service alongside other products. Bhatia, Bhvanani, Chiu, Janakiram, and Silarszky (2008) demonstrated the effects of using mobile money in the improvement in information flow between transacting parties allowing efficiency among the trading without travelling. This was noted particularly for users in rural areas where traders would have needed to travel to urban centres to send and receive money. Hence, mobile money usage results in the reduction in transportation cost and consequently increased customer surplus (Sife, Kiondo and Lyimo-Macha (2010).

\section{Effect of Mobile Money}

Duncombe and Boateng (2009) noted that there were few studies so far conducted on the impact assessment of mobile money due to the fact that many such innovations were still at their adolescent stages of implementation. Kumbhar (2011) identified important indicators which can be applied in the assessment of alternative banking services as means of financial inclusion. The indicators were broadly categorized as qualitative, quantitative and impact indicators, where impact indicators included change in income, change in savings, change in living standards, the level of indebtedness, and the level of banking habits. Furthermore, a review of empirical studies revealed positive impact on savings, information exchange, increased income and remittances and reduced costs (Demombynes \& Thegeya, 2012).

\section{Problems Associated with Mobile Banking}

Experts in the Silicon Valley say many hurdles still need to be cleared to move the mobile payment system into the mainstream. These include technology challenges as well as high upfront costs, security and enough of the right type of phone. Challenges in technological advancement and the high cost of adoption to both consumers and service providers, are other challenges facing MPS as well. Acceptance is another challenge facing MPS. Despite the unique features of MPS it is not widely accepted in Ghana. There are no guarantees that MPS technology will catch on in Ghana, as it has in places such Japan, Korea, Malaysia, Kenya, South Africa and the rest. Thus, the survey to be conducted as part of this project to find out the challenges to the adoption of MPS in Ghana, will evaluate this challenge in more in-depth. Other issues are that of compliance procedures between the banks, operators and regulatory authorities and interoperability of the system (Shiels, 2009).

\section{MATERIALS AND METHODS}

The study used cross-sectional survey design, which is defined as a study which gathers information at only one point in time (Frey, Botan and Kreps, 1991). The use of cross sectional study implied that data were collected in a particular point in time in the study area with expectation that variables were not likely to change. Data was collected in the months of April and May, 2015.

The study was carried out in the Akuapim North Municipal area and a simple random sampling technique was applied to select the Akuapim North Municipal area. A list of rural communities was drawn and the names were put in a container and then the community was chosen. Aboabo is one of the numerous rural communities in Akuapim North. The community is 
divided into two (2), Aboabo No. 1 and Aboabo No. 2. The community's major economic activities include farming, forestry and trading to a lesser extent.

\section{Sampling procedure and data collection}

A multistage cluster sampling technique was used in selecting the household. The sample was drawn in four stages as follows:

1. Selection of study districts. The first stage involved a random selection of one district out of twenty six (26) districts/municipal in the Eastern Region. A list of the twenty six (26) municipal/districts Assemblies forming the study population was drawn and the names were put in a container. Using simple random sampling technique, Akuapim North Municipal Assembly was chosen.

2. Sampling of the rural communities. A list of rural communities from the chosen municipal area was drawn and the community numbers were put in a container. Using simple random sampling technique, Aboabo was chosen.

3. Sampling of households. This was the last stage where the sampling units for the survey were the households with the mobile phone and the respondent was the anyone with a mobile phone in the household. Purposive sampling technique was used to select members of the focus group discussion (FGD).

The study used a survey method to gather primary data, where the questionnaire and focus group discussions were the main instrument for data collection. Likert type questions were used because the measured constructs on the impact of mobile money is quite broad and contain multiple aspects that cannot easily be measured with single items. Participants in the focus group discussions were purposively selected based on their socioe-conomic characteristics and experience in using the mobile money services. Each focus group discussion was composed of eight (8) members. Two focus group discussions were conducted for this study, with four key themes usage, remittances, savings and loan.

\section{The study community}

About 51\% of the population aged 11 years and older in the Aboabo community are literate. Literacy is higher for the male (68\%) population than females (53\%). In terms of occupation of the employed population, majority (61\%) are engaged as skilled agricultural and forestry. The second commonest (29\%) occupation of the employed is trade followed by service related work (10\%). The major industry engaging majority of the workers in the community is agriculture (ANMA, 2015).

$90 \%$ of the community is engage in agriculture; there are more agricultural households in the community. The major agricultural activity in the community is crop farming (86\%), followed by livestock rearing (12\%) and tree planting (3\%). The use of mobile phones in the community is quite extensive with $60 \%$ percent of the population having mobile phones. There are relatively more males (52\%) than females (49\%) having mobile phones. The use of internet is also quite low, with only about $6 \%$ of the population ((ANMA, 2015).

\section{Ethical issues}

Informed consent was sought from community leaders and the community members/study participants. Great care was taken to include only those who consented and the information part of the informed consent was taken very seriously. All the study participants were repeatedly told the purpose and methods of the study. Great care was taken to exclude those who either failed to understand the purpose of the study or did not consent to the study. 
A respectful and collaborative approach to knowledge production, involving constructive dialogue minimised the risk of misinterpretation. This included clearly outlining the research objectives, the structure and focus of the exercise, the rights of the respondent and the practical importance of the research, and allowed respondents to ask questions in the process. Written and oral consent of the respondents was sought before each of the interview or focus group discussions. Measures to ensure the confidentiality of respondents included the assurance of anonymity of participants, the use of pseudonyms, and re-wording of identifying characteristics in the presentation of results.

\section{RESULT}

The profile of the participants is shown in Table 1 below, where the most of them were males (56\%). Majority of the participants fall within the age bracket of 26years-35years (41\%). The commonly attained educational level by the participants is Junior high school/Middle school qualification (41\%) and $61 \%$ of the respondents (forming the majority) were self-employed.

Table 1: Participants' Profile

\begin{tabular}{|c|c|c|}
\hline $\begin{array}{l}\text { Demographic characteristics } \\
\text { Gender }\end{array}$ & Frequency & Percentage (\%) \\
\hline Male & 56 & 56 \\
\hline Female & 43 & 43 \\
\hline Total & 100 & 100 \\
\hline \multicolumn{3}{|l|}{ Age } \\
\hline $11-15$ & 3 & 3 \\
\hline $16-25$ & 21 & 21 \\
\hline $26-35$ & 41 & 41 \\
\hline $36-45$ & 26 & 26 \\
\hline $46-55$ & 18 & 18 \\
\hline $55+$ & 12 & 12 \\
\hline Total & 100 & 100 \\
\hline \multicolumn{3}{|l|}{ Education } \\
\hline None & 5 & 5 \\
\hline Primary & 24 & 24 \\
\hline \multicolumn{3}{|l|}{ Senior high } \\
\hline school/Technical/Vocational & 23 & 23 \\
\hline Tertiary & 7 & 7 \\
\hline Total & 100 & 100 \\
\hline \multicolumn{3}{|l|}{ Occupation } \\
\hline Employed & 19 & 19 \\
\hline Self employed & 69 & 69 \\
\hline Unemployed & 12 & 12 \\
\hline Total & 100 & 100 \\
\hline
\end{tabular}

\section{Use of Mobile money services}

Table 2 below shows the usage of mobile money service by the study participants, where deposit, withdrawals (cash-in and cash-out), fund transfers and airtime purchase were the most patronised services. This is a sign of high usage of the innovative services provided by the telecom companies; however payment of bills was not frequently used. 
Table 2: Usage of mobile money services

\begin{tabular}{|lcc|}
\hline Services & Frequency & Percentage (\%) \\
Deposits & 41 & 41 \\
Withdrawal & 67 & 67 \\
Fund transfer & 74 & 74 \\
Airtime purchase & 9 & 9 \\
payment of bills & 2 & 2 \\
\hline
\end{tabular}

Results from the focused group discussion (FGDs) also showed that participants had used the mobile money services and the most used services were the funds transfer (receiving remittances) and buying airtime. The FGD members indicated that mobile money had improved their access to financial services as most of the members no longer travelled long distances to access the nearest mobile money agent. On the incidence of use the study found that they used the service several times per week to several times per month with those employed using it more often. The FGD members indicated that with the arrival of mobile money services, sending and receiving money had become more convenient, cheaper, faster and easier.

"MTN mobile money has helped me to reduce transport costs, formerly I used pay for transport to go to the bank to collect that my son sends to me every month. But now he sends the money to my mobile money account which l easily withdraw from the agent in our community here. So I now save that money I used to pay the drivers to take me to the bank in Akropong (Municipal capital)

Figure 1: Frequency of mobile money usage

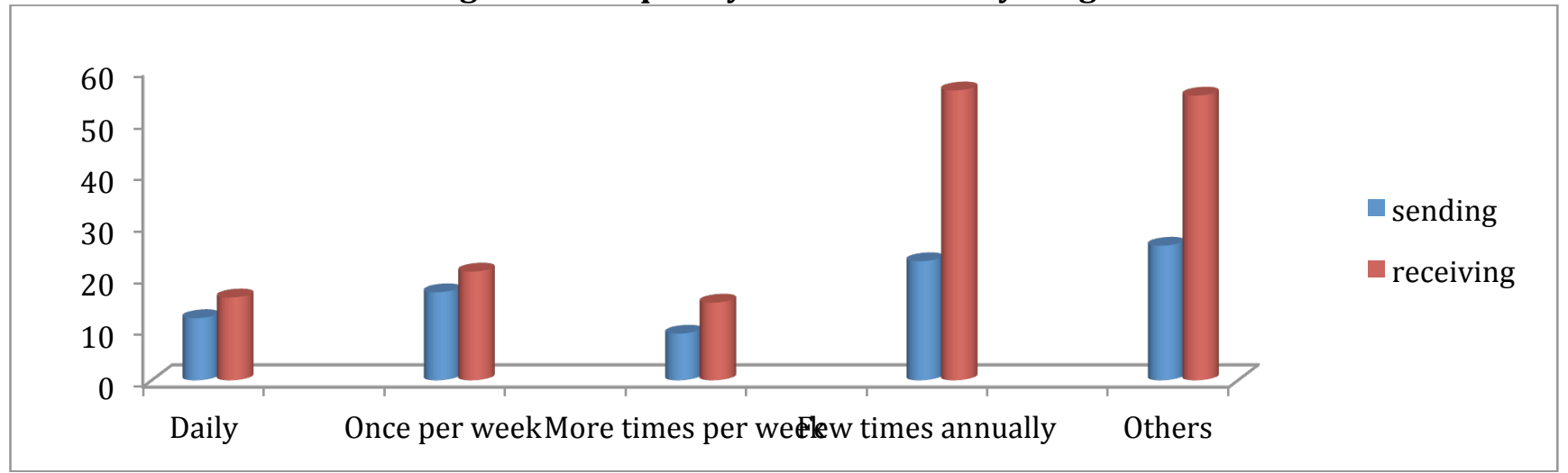

Twelve (12) respondents indicated they sent money daily using mobile money services (MMS), while sixteen (16) received money through the MMS on a daily basis. Seventeen (17) participants sent money once per week while twenty one (21) people received money once every week. Nine (9) respondents sent money more than once per week and fifteen (15) people indicated that they received money more than once per week. Twenty three (23) participants sent money using MMS a few times in a year while fifty six (56) people received money through the MMS a few times annually. Also, under the others category, twenty six (26) participants used the MMS to send money and fifty five (55) received money through the MMS.

More respondents (60\%) indicated having both sent and received mobile money compared to those that had either only sent $(31 \%)$ or only received $(28 \%)$. On the whole, clients that send money seem active with $41 \%$ having at least one transaction per month as compared to those 
who receive money, where $49 \%$ have at least a transaction per month. Among age groups, respondents send more than they do receive, with the exception of the 26-35 age group, who tend to send (58\%) and receive (46\%) likewise; and respondents below 20 years of age who receive (61\%) more than send (18\%). Perhaps this indicates the fact that people in this age group are basically dependent.

\section{Reasons for using mobile money services}

Table: key reasons for using mobile money

\begin{tabular}{|c|c|c|}
\hline Reasons & Frequency & Percentage \\
\hline Immediate family & 58 & 58 \\
\hline $\begin{array}{l}\text { Payment for goods and } \\
\text { services }\end{array}$ & 31 & 31 \\
\hline Payment of bills & 5 & 5 \\
\hline Others & 23 & 23 \\
\hline
\end{tabular}

Exploring the key reasons that participants use mobile money transfers, support for immediate family members led in all cases. Amongst the group that both sends and receives mobile money, payment for goods and services is the most common reason with $38 \%$ stressing this as the basic purpose for which they receive money. Nevertheless when it comes to sending money, $63 \%$ among the same group indicate supporting immediate family compared to $27 \%$ for goods and services as the basic reason for employing mobile money services.

\section{Other forms of mobile transactions}

Use of mobile money for other types of transactions besides money transfers is emerging. The most common usage is to buy airtime from your provider as indicated in Figure 4. Users can buy airtime (or credit) either for themselves or others by entering a destination number on the

Other transactions have been introduced across different networks, but are yet to catch on like payment of cable television bills (DStv, Gotv) and more recently school fees or tuition, electricity and water bill.

On the key benefit of using mobile money for these other transactions most (52\%) responded that mobile is faster than other methods. Other benefits included having their mobile phone (hence their mobile money) with them all the time (55\%) and cheaper than other methods (71\%). Contrariwise, participants were worried about the liquidity of agents or their lack of cash (38\%) and the fear of losing one's mobile phone (hence mobile money) by 35\% were given as the topmost drawbacks to mobile money.

\section{DISCUSSION}

Mobile money service has increased financial access and usage by rural communities and has positive impact on remittances with funds transfer (sending and receiving) outstanding on usage. The findings confirm the findings by Mas \& Morawczynski (2009) and Mbiti \& Weil (2011). However, contrary to their findings the savings and loan facility had not registered use and pattern changes among the groups interviewed. Though there is probability of use if mobile money service providers increased awareness through educational programs as indicated by the interest generated during the discussion. The study proved that there were 
mixed outcomes on the effect of mobile money on user incomes, however, Mbiti \& Weil (2011) using quantitative approach showed that M-Pesa in Kenya mobile money increased incomes of users. Kumbhar (2011) in a related studies reached similar conclusions. The indifference shown on savings and loans could be due to the fact that these were new product offerings that are hardly a year old whereas funds transfer, deposit and withdrawals (cash-in and cash-out), bill-payments and airtime purchase have been there for some time hence their popularity.

\section{CONCLUSION}

Mobile money service has a positive impact on financial inclusion of rural folks as demonstrated by the access and usage of mobile money by the rural people. It has increased their access to affordable financial services within their locality. Most remarkable was the positive effect on remittance and reduced cost of transaction. The savings and loan facilities were not popular despite being available to these deemed excluded sections of the population.

\section{RECOMMENDATIONS}

The researchers recommend that mobile money service providers through bank partnerships should carry out educational programs aimed at informing and educating rural people to save through mobile money service. This will help explain the relationship between their savings and loan scheme.

\section{ACKNOWLEDGEMENT}

The authors are grateful to the Aboabo community in the Akuapim North Municipal Assembly area and the Presbyterian University College, Ghana.

\section{References}

Adams Jr., R.H., \& Cuecuecha, A. (2013). The impact of remittances on investment and poverty

Aker JC and Mbiti IM (2010) Mobile phones and economic development in Africa. Journal of Economic Perspectives 24: 207-32.

Alleman, J., \& Rappoport, P. (2010). Mobile Money: Implications for Emerging Markets, Communications \& Strategies, No. 79, 3rd Quarter.

Aryeetey, E. (1994) Informal Savings Collectors in Ghana: can they intermediate? Accessed:

Bhatia, D. Bhvanani, A., Chiu, R. W., Janakiram, S., \& Silarszky, P.(2008). The role of Mobile Phones in sustainable Rural Poverty Reduction, ICT Policy Division, Global Information and Communication Departmment (CGICT).

Boardi, R. A., Boateng, R., Hinson, R., \& Epoku, R.(2007). Preliminary insights into M-commerce adoption in Ghana, Information Development, Vol. 23(4), pp 253-265.

Boateng, R. (2011). Mobile phones and micro-trading activities- conceptualising the link, Emerald, Vol. 13(5), 4862.

December 27th from: http://www.allbusiness.com/public-administration/national-securityinternational/433294-1.html

Demombynes, G and Thegeya A (2012), Kenya's Mobile Revolution and the promise of mobile saving, The World Bank, Africa region, Policy research working paper 5988,Washington, DC.

Demombynes, G and Thegeya A (2012), Kenya's Mobile Revolution and the promise of mobile saving, The World Bank, Africa region, Policy research working paper 5988,Washington, DC.

Donner, J. and C. A. Tellez (2008). "Mobile banking and economic development: Linking adoption, impact, and use." Asian Journal of Communication 18(4): 318-322.

Duncombe R, Boateng R (2009). Mobile phones and financial services in developing countries: a review of concepts, methods, issues, evidence and future research directions. Third World Quarterly 30: 1237-1258. 
Frey L.R, Botan C.H, Kreps G L (1991), Investigating communication: An introduction to research methods (2nded), Prentice Hall, Englewood Cliffs, NJ.

in Ghana. World Development, 50, 24-40.

Ivatury, G. and M. Pickens (2006). Mobile Phone Banking and Low-Income Customers: Evidence from South Africa. Washington, DC, CGAP and the United Nations Foundation.

Jack W and Suri T (2011). Mobile money: the economics of M-PESA, NBER Working Paper No.16721 (National Bureau of Economic Research, Cambridge, MA).

Kumbhar, M., V. (2011). A Multinational Concept Instrument (eFI-Test) for Assessment of E-Financial Inclusion. National Conference on Accounting of Social Sector Development, Dpt of Economics, Shivaji University, Kolhapur, India, February 1-2, 2011. Leech

Leishman, P. (2010). Understanding the Unbanked Customer and Sizing the Mobile Money Opportunity. GSMA Mobile Money for the Unbanked Annual Report 2009, GSM Association.

Mas, I. and K. Kumar (2008). Banking on Mobiles: Why, How, for Whom? Washington DC, CGAP.

Mas, I., \& Radcliffe, D. (2011). Scaling Mobile Money, Journal of Payment Strategy \& Systems, Vol. 5(3) 298-315.

Mendes, S., E. Alampay, et al. (2007). The innovative use of mobile applications in the Philippines - lessons for Africa. Sida Publications, Sida.

Mirzoyants A (2012). Mobile Money in Uganda: Use, Barriers and Opportunities (InterMedia, Washington DC).

Morawczynski, O. (2009). Examining the Usage and Impact of Transformational M-Banking in Kenya.

Internationalization, Design and Global Development. N. Aykin, Springer Berlin / Heidelberg. 5623: $495-504$.

Morawczynski, O., \& Pickens, M. (2009). Poor People Using Mobile Financial Services: Observation on Customer Usage and Impact from M-Pesa, CGAP

Nandhi, M., A. (2012). Effects of mobile banking on the savings practices of the low-income users: The Indian Experience, Institute for Money, Technology \& Financial Inclusion (IMTFI), WORKING PAPER NO 7, Jesus and Mary College, University of Dehli, India.

Ndiwalana, A. and O. Popov (2008). Mobile Payments: A Comparison between Philippine and Ugandan Contexts. IST-Africa 2008. P. Cunningham and M. Cunningham. Namibia, IIMC.

Oluwataya, I. (2013). Banking the unbanked in rural Southwest Nigeria: Showcasing mobile phones as mobile banks among farming households, Journal of Financial Services Marketing Vol. 18, 65-73. Radcliffe

Philippine migrants’ exchange rate shocks. Economic Journal, 118, 591-630.

Shiels M., "Challenges to a 'cashless' world” [HTML], BBC, 13th February, 2009. www.bbc.co.uk, data accessed: 20th October 2009

Sife, S., A., Kiondo, E., \& Lyimo-Macha, G. J. (2010). Contributions of Mobile Phones To Rural Livelihoods and Poverty Reduction in Mororgoro Region, Tanzania, Electronic Journal of Information Systems in Developing Countries (EJISDC), Volume 42(3), 1-15.

Wishart, N. (2006). Micro-payment systems and their application to mobile networks: Examples of Mobile enabled services in the Philippines. Infodev publications, IDRC.

Yang, D. (2008). International migration, remittances, and household investment: evidence from 